\title{
THE IMPACTS OF DIVERSIFIED OPERATIONS ON LENDING OF FINANCIAL INSTITUTION
}

\author{
Jer-Shiou Chiou', Bor-Yi Huang ${ }^{2}$, Pei-Shan Wu ${ }^{3}$, Chun-Ni Tsai ${ }^{4}$ \\ Shih-Chien University, Ching Yun University, 70 Ta-Chih Street, \\ Taipei 104, Taiwan

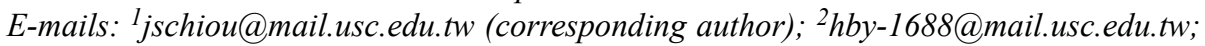 \\ 3pasun@cyu.edu.tw; ${ }^{4}$ chunhsin2003@yahoo.com.tw
}

Received 21 March 2011; accepted 07 June 2011

\begin{abstract}
This study explores the impacts of bank's diversified operations on their loans, the threshold effect of bank's derivatives trading and the impacts on their financial behaviors are investigated. The results show that there are two separate regime effects for banks in large-sized and medium-sized, and three regime effects for banks in small to medium-sized. Derivatives trading not only make banks easier to diversify their credit risk exposure, but also alter their lending behaviors.

As an example of large banks, when banks derivatives' trading is more than US\$61 billion, an increase in banks assets will associate with a corresponding increase in loans to SMEs. If trading in derivatives by the banks is less than the threshold value, the banks will make loans less available to SMEs when there is an increase in banks assets. In addition, when banks are less aggressive in derivatives trading, debt ratio, pre-tax earnings and the SME credit guarantee balance all have significantly positive associations with loans to SMEs.
\end{abstract}

Keywords: panel smooth transition regression, threshold value, derivatives trading, loan on SMEs.

Reference to this paper should be made as follows: Chiou, J.-S.; Huang, B.-Y.; Wu, P.-S.; Tsai, C.-N. 2012. The impacts of diversified operations on lending of financial institution, Journal of Business Economics and Management 13(4): 587-599.

JEL Classification: G21, G28.

\section{Introduction}

The important roles played by small- and medium-sized enterprises (SMEs) within an economy have drawn the attention of a considerable number of studies over recent decades, essentially because such enterprises are regarded not only as major contributors of sources of employment and national income, but also crucial drivers of innovation and economic growth (OECD 2009). The importance of SMEs to any economy is obvious; in Japan, they account for 99 percent of the total number of enterprises, whilst in the European Union (EU), over 99 percent of all enterprises are small or medium sized. A similar situation is also found in Taiwan, where SMEs were still found to be accounting for over 97 percent of the total number of firms in 2008. 
Despite the fact that in most of the developed countries, large firms invariably contribute a significant proportion of all economic activity, SMEs continue to play a crucial role in terms of the share of total employment. In addition to representing the vast majority of firms, they are also dominant in many sectors of economic activity where they continue to provide sources of new products and ongoing technological innovation (Cull et al. 2005).

There are a number of fundamental financial characteristics generally associated with small enterprises; for example, they retain a greater share of earnings than large enterprises (Keasey, McGuinness 1990), whilst it is also easier for them to acquire funding from the private equity and debt markets than from the public markets. However, as a result of the restrictions on SMEs, particularly with regard to their lack of collateral, such firms are invariably faced with a number of impediments to their survival and growth, which obviously includes limited access to sources of funding.

On the other hand, from the examinations of earlier credit market innovations, such as loan sales and securitizations, several studies have found that banks tend to use every opportunities to diversify their credit risk exposure by increasing their overall lending ${ }^{1}$. Such risk transference is frequently cited as a stabilizing factor within the financial system of an economy, effectively reducing exposure concentration by individual banks and spreading the overall credit risk (Geithner 2006). Although credit derivatives are basically innovations promoting credit risk management and making it easier for banks to diversify their credit risk exposure, they have, nevertheless, tended to deviate from their original function.

The primary aims of this study are therefore to investigate the impacts of the various financial variables on SME lending, along with consideration of the threshold effect of derivatives management, using survey data on a sample of 28 banks covering the period from Q1 1998 to Q2 2009. The remainder of this study is presented as follows. The research methodology adopted for this study is discussed in section 3, followed in section 4 by a description of the data and the presentation of the empirical results. Finally, the conclusions drawn from this study are presented in section 5.

\section{Reviews}

Many of the related studies within the extant literature note that the legal and financial environment of a country directly affects access to external financing ${ }^{2}$; as a consequence, SMEs tend to rely primarily on internal resources, followed by debt, with outside equity being the last resort (Myers, Majluf 1984).

It should, however, be noted that between debt and equity financing, the latter is found to be less frequently adopted by small enterprises (Hughes, Storey 1994; Hughes 1997), which therefore implies that small-firm entrepreneurs tend to prefer to finance their projects using methods capable of minimizing the risk of outside control whilst also helping to avoid externalities which can ultimately lead to ownership dilution.

\footnotetext{
${ }^{1}$ See for example: Cebenoyan and Strahan (2004), and Goderis et al. Wagner (2006).

${ }^{2}$ Examples include Rajan and Zingales (1998) and Demirgüç-Kunt and Maksimovic (1998).
} 
Indeed, their lack of accessibility to financing has been identified in many business surveys as one of the greatest obstacles to the survival and growth of SMEs in many economies (European Commission 2002). Nevertheless, despite such recognition of the problem, banks still appear to prefer to lend to large enterprises rather than SMEs. Thus, informal sources of financing, such as friends or private investors, tend to be used significantly more by small firms than by large firms. However, the financing available from such sources is extremely restricted; indeed, as noted in a recent survey carried out by the World Bank, large firms, both local and foreign, generally have greater accessibility to bank credit than small firms.

However, according to a survey on small businesses undertaken by Cole, Wolken and Woodburn (1996), commercial banks are the most important source of credit to small firms. Several other studies within the extant literature have therefore focused on the relationships between small business lending and the size of the banking institutions, with many of these studies having found that the small banking institutions are inclined to allocate greater proportions of their assets to the provision of small business loans, as opposed to lending to large institutions ${ }^{3}$.

At the same time, the growth of the financial derivative markets, as a whole, has followed a pattern similar to that which we might expect to see for any financial innovation, with the banking institutions experiencing increasing acceptance amongst their clients (Remolona 1993). This is despite the fact that derivatives are concentrated amongst a relatively low number of financial intermediaries (Gorton, Rosen 1995). However, the past decade has witnessed extraordinary growth in the financial derivatives markets on a global scale, with an obvious significant increase between 2001 and 2007.

Nevertheless, they have tended to deviate from their original function. Under the traditional model of bank lending, banks had previously relied upon the spread between the deposit and loan interest rate as a source of profit, with the banks' credit role involving originating the loan, holding the loan on the balance sheet (funding it) and holding and managing the associated credit risk. These days, however, financial institutions are frequently seen to be trading in derivatives, actively utilizing the price spread to accrue greater profits.

Clearly, business loans affect the profitability of the banks (Sufian, Habibullah 2009), and thus, the integrity of their survival and development; in contrast, financial innovation enables such institutions to use derivatives to make profits. As a result, such instruments have tended to replace much of the prior lending over recent years. This not only influences the banks' fundamentals, but it also affects their level of credit supply, particularly to SMEs.

\section{Methodology}

A prime example of a parameter heterogeneity model is the panel threshold regression (PTR) model which was developed by Hansen (1999) to specifically allow the regression coefficients to vary over time. González, Teräsvirta and van Dijk (2005) went on

\footnotetext{
${ }^{3}$ See Strahan and Weston (1996) and Peek and Rosengren (1998).
} 
to develop the panel smooth transition regression (PSTR) model which modifies the original PTR model by including a transition function. This brings about a slight change in the regression coefficients as the system moves from one group to another, thereby solving the problem of the jump effect in the original PTR model. We therefore adopt the PSTR model to carry out our research methodology in the present study. The panel observations in this model are divided into a number of different homogenous groups or regimes, depending on whether the threshold variable is lower or higher than the threshold value, $c$.

The panel smooth transition regression (PSTR) model is a fixed effects model of exogenous regressors with two particular characteristics. It can vary across individuals and over time as in a linear heterogeneity panel model with coefficients. In addition, the heterogeneity in the regression coefficients assumes that these coefficients are under continuous functions of an observable variable, a transition function which fluctuates between a finite number of extreme regimes (but often two). Based upon González et al. (2005), the PSTR model can be expressed as:

$$
y_{i t}=u_{i}+\beta^{\prime}{ }_{0} x_{i t}+\beta^{\prime} x_{i t} g\left(q_{i t} ; \gamma, c\right)+\varepsilon_{i t} \text {. }
$$

Let $i=1, \ldots, N$, and $t=1, \ldots, T$, where $i$ and $t$ respectively denote the individual and time of the panel; the dependent variable $y_{i t}$ is a scalar; $x_{i t}$ is a $k$-dimensional vector of exogenous variables representing the time-variance; $u_{i}$ is the fixed effect for individuals, and $\varepsilon_{i t}$ is the error term. The transition function $g\left(q_{i t} ; \gamma, c\right)$ is a continuous function which is normalized and limited to between 0 and 1 , where $q_{i t}$ is the threshold variable, which comprises of an exogenous variable or a combination of the lagged endogeneity. In light of Granger and Teräsvirta (1993), Teräsvirta (1994) and Jansen and Teräsvirta (1996) within a time-series context, and the work of González et al. (2005) within the context of the panel framework, the logistic specification used for the transition function is expressed as:

$$
g\left(q_{i t} ; \gamma, c\right)=\left[1+\exp \left(-\gamma \prod_{j=1}^{m}\left(q_{i t}-c_{j}\right)\right)\right]^{-1},
$$

where $\gamma>0 ; c_{1} \leq c_{2} \leq \ldots \leq c_{m} ; c=\left(c_{1}, \ldots c_{m}\right)^{\prime}$ is an $m$-dimensional vector of location parameters; and $\gamma$ is the slope parameter identifying the smoothness of the transition.

In general, the transition function may result in the setting up of $m=1$ and $m=2$. When $m=1$, two extreme regimes will be created; thus, that with an increase in $q_{i t}$, the coefficients will move from $\beta_{0}$ to $\beta_{0}+\beta_{1}$. For $\gamma \rightarrow \infty, g\left(q_{i t} ; \gamma, c\right)$ will be an indicator function $\mathrm{I}\left[q_{i t}>c_{1}\right]$ with $\mathrm{I}[\mathrm{A}]=1$ when event 'A' occurs, otherwise 0 . When $m=1$ and $\gamma \rightarrow$ $\infty$, the PSTR model reduces to the PTR model of Hansen (1999). When $m=2, \gamma \rightarrow \infty$ (referred to as the exponential model), the model will be divided into three regimes, with the two similar regimes on either side differing from the central regime. Conversely, when $\gamma \rightarrow 0$, the model reverts to a homogenous or linear function without any obvious transition structure. 
González et al. (2005) argue that from an empirical viewpoint, it is sufficient to consider $m=1$ or $m=2$ to capture the non-linearities attributable to the regime. However, the PSTR model which extends for more than two different regimes is expressed as:

$$
y_{i t}=u_{i}+\beta^{\prime}{ }_{0} x_{i t}+\sum_{j=1}^{r} \beta^{\prime}{ }_{j} x_{i t} g_{j}\left(q_{i t}^{(j)} ; \gamma_{j}, c_{j}\right)+\varepsilon_{i t} \text {. }
$$

The transition function $g_{j}\left(q_{i t}{ }^{(j)} ; \gamma_{j}, c_{j}\right), j=1, \ldots, r$ is determined by Equation (2), where $r+1$ is the number of regimes and $g_{j}\left(q_{i t}(j) ; \gamma_{j}, c_{j}\right), j=1, \ldots, r$ are the transition functions. In particular, the multiple regime Equation (3) is an obvious alternative in diagnostic tests of no residual heterogeneity.

\section{Data source and empirical results}

\subsection{Data}

The sample for the present study is provided by data on 28 domestic banks in Taiwan covering the period from Q1 1998 to Q2 2009, obtained from government departments of the Central Bank of the Republic of China (Taiwan) and Banking Bureau of Financial Supervisory Commission, the dependent variable is bank lending to SMEs. Using the PSTR model, panel data is applied in order to determine the threshold effects of derivatives trading. The aim is to investigate the ways in which the financial variables affect SME lending. The 28 banking institutions are classified as large-, medium-, small to medium- and small-sized banks, based upon their average total assets for the year 2009. The threshold variable, national amounts outstanding of derivatives that calculate by: interest rate contracts, foreign exchange and gold contracts, equity-linked contracts, commodity contracts, credit contracts and other contracts. It will get a value after sum of these six items. That is available as the threshold variable.

After applying the correlation test, we select five independent variables: total assets $(T A)$; debt ratio $(D R)$; pre-tax earnings $(P T E)$; SME credit guarantee balance ${ }^{4}(C G B)$; and the investment growth rate $(I G)$. The descriptive statistics of the variables are presented in Table 1.

The mean $C G B$ is US\$236.9 million (max US\$1.73 billion, min 0); this indicates that although banks may have applied for the credit guarantee fund, the available credit has not been sufficiently taken up by the SMEs. Furthermore, the average investment growth rate (relative to the same period in the previous year) is found to be 14.73 percent (max 372.1 percent, $\min -75.1$ percent), which clearly reveals considerable fluctuations in the investment strategies of banks.

\footnotetext{
${ }^{4} C G B$ refers to a situation in which the amount of credit in guarantee funds is committed to SMEs, if SMEs can not repay their loans.
} 
Table 1. Results of variables descriptive statistics

\begin{tabular}{lcccc}
\hline Variables & Mean & Maximum & Minimum & Std. Dev. \\
\hline TA & 24,900 & 130,600 & 2,970 & 23,051 \\
DR & 1.02 & 2.27 & 0.41 & 0.24 \\
PTE & 58.7 & 1,209 & $-1,616$ & 179.51 \\
CGB & 236.9 & 1,730 & 0.00 & 319.36 \\
IG & 14.73 & 372.10 & -75.10 & 44.35 \\
\hline
\end{tabular}

\subsection{Empirical results}

Based upon the observations of the present study, the financial derivatives market in Taiwan is found to have grown in much the same way as might be expected of any financial innovation, demonstrating a manifold increase from the level in mid- 2001 to that in 2007. We therefore assume that when banks deal in loans, there are also threshold effects with regard to derivatives trading.

\subsubsection{Large-sized banks (TA greater than US\$33.6 billion)}

There are a total of eleven banks falling into the large-sized category. In carrying out the evaluation of these banks, the first step necessarily involves the application of a homogeneity test to determine whether the PSTR model is non-linear. The results are presented in Table 2, which shows that after applying the linearity 'likelihood ratio test' (LRT), the hypothesis of linearity is rejected at the 1 percent significance level $(F=22.488, p$-value $=0.000)$.

Table 2. Determination of the homogeneity tests for large-sized banks

\begin{tabular}{|c|c|c|}
\hline LRT Tests $(m=1)$ & Statistic & $p$-value \\
\hline $\mathrm{H}_{0}:$ Linear model & \multirow[b]{2}{*}{22.488} & \multirow[b]{2}{*}{0.000} \\
\hline $\mathrm{H}_{1}$ : PSTR model (with at least one threshold variable), $r=1$ & & \\
\hline $\mathrm{H}_{0}:$ PSTR with $r=1$ & \multirow{2}{*}{4.231} & \multirow{2}{*}{0.517} \\
\hline $\mathrm{H}_{1}:$ PSTR with (at least) $r=2$ & & \\
\hline
\end{tabular}

The determination of the number of regimes for large-sized banks is shown in Table 3, whilst the parameter estimates and the impact of the exogenous variables are presented in Table 4. It is found that the model is non-linear, with one threshold value being confirmed under the LRT tests.

Table 3. Determination of the number of regimes for large-sized banks

\begin{tabular}{lc}
\hline & $(m=1)$ \\
\hline No. of Thresholds $r(m)$ & $1(1)$ \\
RSS & 8009.013 \\
AIC & 21.2559 \\
BIC & 21.3562 \\
\hline
\end{tabular}


An interesting finding from Table 4 is that when separated by a threshold value of US\$61 billion in derivatives trading, the outcomes for the estimated coefficients, in terms of both significance and direction, are virtually opposite. When banks exhibit more aggressive derivatives trading, the impact of total assets on SME loans is 0.0399 at the 1 percent significance level; that is, with an increase in total assets, there will be a corresponding increase in loans to SMEs.

Table 4. Estimation results of the one-threshold PSTR model for large-sized banks

\begin{tabular}{|c|c|c|c|c|}
\hline \multicolumn{2}{|c|}{ Variables } & Coefficient & Heteroskedasticity (S.E.) & T-statistics \\
\hline \multirow{5}{*}{$\beta_{0}^{\prime}=$} & \multirow{5}{*}{$\begin{array}{l}T A_{i t} \\
\mathrm{D} R_{i t} \\
\mathrm{P} T E_{i t} \\
\mathrm{C} G B_{i t} \\
\mathrm{I} G_{i t}\end{array}$} & 0.0185 & 0.0115 & 1.6174 \\
\hline & & $25.0730 * * *$ & 8.3501 & 3.0027 \\
\hline & & $0.9875^{* * *}$ & 0.3526 & 2.8009 \\
\hline & & $8.0977 * * *$ & 1.3610 & 5.9498 \\
\hline & & -0.0050 & 0.0128 & -0.3941 \\
\hline \multirow{5}{*}{$\beta_{1}^{\prime}=$} & & $0.0399 * * *$ & 0.0132 & 3.0355 \\
\hline & $\begin{array}{l}1 A_{i t} \\
\mathrm{D} R\end{array}$ & -0.3875 & 2.5973 & -0.1492 \\
\hline & $\begin{array}{l}\mathbf{D} \boldsymbol{N}_{i t} \\
\mathbf{p} T F\end{array}$ & -0.8239 & 0.5081 & -1.6217 \\
\hline & C $G B_{i t}$ & $-8.6471 * * *$ & 1.2354 & -6.9996 \\
\hline & $\mathrm{I} G_{i t}$ & -0.0106 & 0.0168 & -0.6314 \\
\hline \multicolumn{3}{|l|}{$c$} & 183.6563 & \\
\hline \multicolumn{3}{|l|}{$\gamma$} & 12.6374 & \\
\hline \multicolumn{3}{|l|}{ RSS } & 8009.013 & \\
\hline \multicolumn{3}{|l|}{ AIC } & 2.8352 & \\
\hline \multicolumn{3}{|l|}{$\mathrm{BIC}$} & 2.9355 & \\
\hline
\end{tabular}

SME loan balance $=u_{\mathrm{it}}+\beta_{0}^{\prime}\left(T A_{i t}, D R_{i t}, P T E_{i t}, C G B_{i t}, I G_{i t}\right)+$ $\sum_{j=1}^{r} \beta_{1}^{\prime} g\left(\right.$ derivatives $\left.{ }_{i t}^{j} ; \gamma_{j}, c_{j}\right)\left(T A_{i t}, D R_{i t}, P T E_{i t}, C G B_{i t}, I G_{i t}\right)$.

When banks are less aggressive in derivatives trading, the coefficient of debt ratio, pre-tax earnings and the SME credit guarantee balance all have significantly negative associations with loans to SMEs at the 1 percent significance level. It indicated that if trading in derivatives by the banks is less than the threshold value of US\$61 billion, the banks will make fewer loans available to SMEs.

\subsubsection{Medium-sized banks (TA: US\$13.46 billion - US\$33.6 billion)}

There are a total of five banks in the medium-sized category. The results of homogeneity test are presented in Table 5 which shows that the model is non-linear with one threshold value being confirmed under the LRT tests. 
Table 5. Empirical results of the homogeneity tests for medium-sized banks

\begin{tabular}{lcc}
\hline LRT Tests $(m=1)$ & Statistic & $p$-value \\
\hline $\mathrm{H}_{0}:$ Linear model & 25.904 & 0.000 \\
$\mathrm{H}_{1}:$ PSTR model (with at least one threshold variable), $r=1$ & 5.742 & 0.332 \\
$\mathrm{H}_{0}:$ PSTR with $r=1$ & & \\
$\mathrm{H}_{1}:$ PSTR with (at least) $r=2$ & & \\
\hline
\end{tabular}

The determination of the number of regimes for medium-sized banks is shown in Table 6, whilst the parameter estimates and the impact of the exogenous variables are presented in Table 7.

Table 6. Determination of the number of regimes for medium-sized banks

\begin{tabular}{lc}
\hline & $(m=1)$ \\
\hline No. of Thresholds $r(m)$ & $2(1)$ \\
RSS & 61.7889 \\
AIC & -1.0582 \\
BIC & -0.7742 \\
\hline
\end{tabular}

Table 7. Estimation results of the one-threshold PSTR model for medium-sized banks

\begin{tabular}{|c|c|c|c|c|}
\hline & riables & Coefficient & Heteroskedasticity (S.E.) & T-statistics \\
\hline \multirow{5}{*}{$\beta_{1}^{\prime}=$} & & $2.0495^{* * *}$ & 0.2917 & 7.0249 \\
\hline & $\begin{array}{l}1 A_{i t} \\
\mathrm{D} R\end{array}$ & $17.3838 * * *$ & 5.8262 & 2.9837 \\
\hline & $\begin{array}{l}\mathrm{D} K_{i t} \\
\mathrm{D} T E\end{array}$ & -15.8729 & 19.9394 & -0.7961 \\
\hline & $\mathrm{C} G B_{i t}$ & $-628.7211 * * *$ & 74.0375 & -8.4919 \\
\hline & $\mathrm{I} G$ & $-0.0146^{* * *}$ & 0.0119 & -1.2248 \\
\hline \multirow{5}{*}{$\beta_{2}^{\prime}=$} & & $-0.0334 * * *$ & 0.0238 & -1.3996 \\
\hline & $\mathrm{D} R_{i t}$ & 0.3641 & 1.3476 & 0.2702 \\
\hline & $\mathrm{P} T E$ & $0.2733^{* * *}$ & 0.2632 & 1.0383 \\
\hline & $\mathrm{C} G B_{i t}$ & -0.1395 & 0.5687 & -0.2453 \\
\hline & $\mathrm{I} G$ & -0.0015 & 0.0033 & -0.4564 \\
\hline \multicolumn{3}{|l|}{$c$} & {$[90.4721]$} & \\
\hline \multicolumn{3}{|l|}{$\gamma$} & {$[24.4008]$} & \\
\hline \multicolumn{3}{|l|}{ RSS } & 61.7887 & \\
\hline \multicolumn{3}{|l|}{ AIC } & -1.0582 & \\
\hline \multicolumn{3}{|l|}{$\mathrm{BIC}$} & -0.7742 & \\
\hline
\end{tabular}

SME loan balance $=u_{\text {it }}+\beta_{0}^{\prime}\left(T A_{i t}, D R_{i t}, P T E_{i t}, C G B_{i t}, I G_{i t}\right)+$ $\sum_{j=1}^{r} \beta_{1}^{\prime} g\left(\right.$ derivatives $\left._{i t}^{j} ; \gamma_{j}, c_{j}\right)\left(T A_{i t}, D R_{i t}, P T E_{i t}, C G B_{i t}, I G_{i t}\right)+$ $\sum_{j=1}^{r} \beta_{2}^{\prime} g\left(\right.$ derivatives $\left._{i t}^{j} ; \gamma_{j}, c_{j}\right)\left(T A_{i t}, D R_{i t}, P T E_{i t}, C G B_{i t}, I G_{i t}\right)+\varepsilon_{i t}$. 
As we can see from Table 7, the threshold value of derivatives trading is US\$3.04 million. When the banks exhibit more aggressiveness in their derivatives trading, the coefficients of total assets, debt ratio, SME credit guarantee balance and investment growth rate are all found to be significant at the 1 percent level. The total assets and debt ratio are also found to have positive effects on loans to SMEs, with respective estimates of 2.0495 and 17.3838. With rises in both assets and deposits, banks will tend to increase their lending to SMEs. On the other hand, the SME credit guarantee balance and the investment growth rate are both found to have negative effects on lending to SMEs, with respective estimates of -628.7211 and -0.00146 , which implies that the credit guarantee fund does not provide assurances for SME loans, and that as such, if banks increase their investment, their lending to SMEs will be reduced.

When banks exhibit less aggressiveness in their derivatives trading, the impact of total assets on SME loans is found to be -0.0334 (with significance at the 1 percent level), the coefficient of pre-tax earning is 0.2733 , which is positive, whilst the effects of investment on loans to SMEs are negative in both regimes.

\subsubsection{Small to medium-sized banks (TA US\$6.73 billion - US\$13.46 billion)}

There are a total of eight banks in the category of small to medium-sized banks. As we can see from Table 8, the model is non-linear with two threshold value.

Table 8. Empirical results of the homogeneity tests for small to medium-sized banks

\begin{tabular}{lcc}
\hline LRT Tests $(m=1)$ & Statistic & $p$-value \\
\hline $\mathrm{H}_{0}:$ Linear model & 31.028 & 0.000 \\
$\mathrm{H}_{1}:$ PSTR model (with at least one threshold variable), $r=1$ & 25.301 & 0.000 \\
\hdashline $\mathrm{H}_{0}:$ PSTR with $r=1$ & 3.274 & 0.660 \\
$\mathrm{H}_{1}:$ PSTR model (with at least), $r=2$ & & \\
\hline $\mathrm{H}_{0}:$ PSTR with $r=2$ & & \\
$\mathrm{H}_{1}:$ PSTR with (at least) $r=3$ & & \\
\hline
\end{tabular}

The determination of the number of regimes for the medium-sized banks is provided in Table 9, whilst both the parameter estimates and the impact of the exogenous variables are presented in Table 10, from which we can see that the two threshold values of derivatives trading are US\$5.64 thousand and US\$96.7 thousand, respectively.

Table 9. Determination of the number of regimes for small to medium-sized banks

\begin{tabular}{lc}
\hline & $(m=1)$ \\
\hline No. of Thresholds $\mathrm{r}(\mathrm{m})$ & $2(1)$ \\
RSS & 67.1102 \\
AIC & -1.5426 \\
BIC & -1.3408 \\
\hline
\end{tabular}


Table 10. Estimation results of the two-threshold PSTR model for small to medium-sized banks

\begin{tabular}{|c|c|c|c|c|}
\hline & riables & Coefficient & Heteroskedasticity (S.E.) & T-statistics \\
\hline \multirow{5}{*}{$\beta_{0}^{\prime}=$} & & $0.1749 * * *$ & 0.0438 & 3.9938 \\
\hline & $\begin{array}{l}I A_{i t} \\
\mathrm{D} R\end{array}$ & $-2.3588 * * *$ & 0.8767 & -2.6905 \\
\hline & PTE & $1.1981^{* * *}$ & 1.1496 & 1.0422 \\
\hline & $\mathrm{C} G B$ & $-3.3522 * * *$ & 0.9057 & -3.7012 \\
\hline & $\mathrm{I} G_{i t}$ & $0.0025^{* * *}$ & 0.0017 & 1.5049 \\
\hline \multirow{5}{*}{$\beta_{1}^{\prime}=$} & & $-0.1505 * * *$ & 0.0422 & -3.5698 \\
\hline & $\begin{array}{l}1 A_{i t} \\
\mathrm{D} R\end{array}$ & $2.5567 * * *$ & 0.7912 & 3.2314 \\
\hline & DR & -0.7767 & 1.1897 & -0.6528 \\
\hline & $\mathrm{P} T E_{i t}$ & $4.8223^{* * *}$ & 0.8689 & 5.5498 \\
\hline & {$\left[\begin{array}{l}\mathrm{COB}_{i t} \\
\mathrm{I} G\end{array}\right.$} & $-0.0041 * * *$ & 0.0018 & -2.2365 \\
\hline \multirow{5}{*}{$\beta_{2}^{\prime}=$} & & $-0.0742 * * *$ & 0.0289 & -2.5635 \\
\hline & $A_{i t}$ & 0.5580 & 0.6565 & 0.8500 \\
\hline & $\mathbf{P} T F$ & $-0.5974 * * *$ & 0.2738 & -2.1817 \\
\hline & $\mathrm{C} G B_{i t}$ & $2.0316^{* * *}$ & 0.5139 & 3.9535 \\
\hline & $\mathrm{I} G$ & $0.0036 * * *$ & 0.0012 & 3.0383 \\
\hline \multicolumn{2}{|r|}{$c$} & \multicolumn{3}{|c|}{$[0.1678$ 2.8725] } \\
\hline \multicolumn{2}{|r|}{$\gamma$} & \multicolumn{3}{|c|}{$[0.00124180 .1372]$} \\
\hline \multicolumn{2}{|r|}{ RSS } & \multicolumn{3}{|c|}{67.1102} \\
\hline \multicolumn{2}{|r|}{ AIC } & \multicolumn{3}{|c|}{-1.5426} \\
\hline \multicolumn{2}{|r|}{$\mathrm{BIC}$} & \multicolumn{3}{|c|}{-1.3408} \\
\hline
\end{tabular}

SME loan balance $=u_{\text {it }}+\beta_{0}^{\prime}\left(T A_{i t}, D R_{i t}, P T E_{i t}, C G B_{i t}, I G_{i t}\right)+$ $\sum_{j=1}^{r} \beta_{1}^{\prime} g\left(\right.$ derivatives $\left._{i t}^{j} ; \gamma_{j}, c_{j}\right)\left(T A_{i t}, D R_{i t}, P T E_{i t}, C G B_{i t}, I G_{i t}\right)+\varepsilon_{i t}$.

When trading in derivatives by banks is smaller than US\$5.64 thousand, they are classified as Group 3, followed by Group 2 and Group 1 if trading is in excess of US\$96.7 thousand. All of the variables in Group 1 are found to be significant at the 1 percent level, whilst the relationships with SME lending are 0.1749 for total assets, 1.1981 for pre-tax earnings, and 0.0025 for investment growth rate; that is, with a 1 percent increase in total assets, pre-tax earnings and investment growth rate, there will be an increase of 1.3755 percent in SME lending, whilst the rest two factors lead to a reduction in SME lending. The respective coefficients of debt ratio and SME credit guarantee balance are -2.3588 and -3.3522 , which indicates with an increase of 1 percent in these variables; banks will reduce their lending to SMEs by 5.711 percent.

As compared to Group 1, the results for Group 2 show that the significance and direction of the estimated coefficients are almost the opposite, with the exception of pre-tax 
earnings, which is found to have no significant impact on SME lending. The effects on SME loans in Group 3 are the same as those in Group 2, with the exceptions of the investment growth rate which shows a positive effect, and the debt ratio which has an insignificant effect.

Our observations reveal that total assets, SME credit guarantee balance and the investment growth rate significantly affect SME loans in Groups 1, 2 and 3, but that the debt ratio and pre-tax earnings have uncertain effects.

\subsubsection{Small-sized banks (TA smaller than US\$6.73 billion)}

There are a total of four banks in the small-sized category. Because lending to SMEs of small banks only accounted for 3\% of all banks. Under the hypothetical required condition of PSTR, this study did not explore for the small banks.

\section{Conclusions}

For small- and medium-sized enterprises (SMEs) in most countries, banks have come to represent the main source of access to financing; however, the general characteristics of SMEs have also tended to discourage banks from investing in small firms, and thus, they prefer instead to lend to larger firms, resulting in a worsening of the conditions under which SMEs have to obtain their much needed financing. At the same time, innovations in the derivatives markets over recent decades have also provided banks with a much wider range of options for the application of their funds, a development which may well have severely hindered the ongoing development and survival of SMEs.

We therefore set out in the present study to discuss the relationships among derivatives trading, bank investment, and loans to SMEs. Using panel data on 28 banks classified under four institutional levels, testing the threshold value of their derivatives trading as well as the impact of the financial variables. We find the existence of two regimes in the large-sized and medium-sized banks, and three regimes in the small to medium-sized banks. Credit derivatives not only promote credit risk management, but making it easier for banks to diversify their credit risk exposure.

Surprisingly, we found some conclusive phenomena, that is: bank total asset is positively correlated with their lending to SMEs across the bank size if banks are aggressively in derivatives trading; bank investment is negatively correlated with their lending to SMEs across the bank size if banks are passively in derivatives trading 5 .

It is argued by many policymakers responsible for providing assistance to organizations in the developing countries that small firms have insufficient access to external financing as a result of market imperfections. Thus, there is a need for the development of policies, such as credit guarantees schemes, or limiting the proportion of banks' investment

\footnotetext{
5 This study explores the impacts of bank's diversified operations on their loans, the threshold effect of bank's derivatives trading and the impacts on their financial behaviors. Readers can make cross comparison of results between this study with previous ones which did not consider derivatives trading, such as Cole et al. (1996).
} 
or other instruments, all of which are aimed at increasing bank lending to SMEs and expanding their financing channels. As such the role of the government becomes ever more important in supporting the development of SMEs.

\section{References}

Cebenoyan, A. S.; Strahan, P. E. 2004. Risk management, capital structure and lending at banks, Journal of Banking and Finance 28: 19-43. http://dx.doi.org/10.1016/S0378-4266(02)00391-6

Cole, R. A.; Wolken, J. D.; Woodburn, L. R. 1996. Bank and non-bank competition for small business credit: evidence from the 1987 and 1993 national surveys of small business finances, Federal Reserve Bulletin (November) 82(11): 983-995.

Cull, R.; Davis, L. E.; Lamoreaux, N. R.; Rosenthal, J. L. 2005. Historical Financing of Smalland Medium-Sized Enterprises, NBER Working Papers No. 11695. National Bureau of Economic Research.

Demirgüç-Kunt, A.; Maksimovic, V. 1998. Law, finance, and firm growth, Journal of Finance 53: 2107-2137. http://dx.doi.org/10.1111/0022-1082.00084

European Commission 2002. Highlights from the 2001 Survey. Observatory of European SMEs No. 1. Brussels, Belgium.

Geithner, T. F. 2006. Implications of Growth in Credit Derivatives for Financial Stability. Paper presented at the New York University Stern School of Business Third Credit Risk Conference, held in New York City on 16 May 2006.

Goderis, B.; Marsh, I. W.; Castello, J. V.; Wagner, W. 2006. Bank Behavior with Access to Credit Risk Transfer Markets. Unpublished manuscript.

González, A.; Teräsvirta, T.; van Dijk, D. 2000. Panel Smooth Transition Regression Models, SSE/EFI Working Paper Series in Economics and Finance No. 604.

Gorton, G.; Rosen, R. 1995. Corporate control, portfolio choice, and the decline of banking, Journal of Finance 50: 1377-1420. http://dx.doi.org/10.2307/2329321

Granger, C. W. J.; Teräsvirta, T. 1993. Modelling Non-linear Economic Relationships. Oxford, UK: Oxford University Press.

Hansen, B. E. 1999. Threshold effects in non-dynamic panels: estimation, testing and inference, Journal of Econometrics 93: 334-368. http://dx.doi.org/10.1016/S0304-4076(99)00025-1

Hsiao, C. 2003. Analysis of Panel Data. 2nd ed. Cambridge, UK: Cambridge University Press. http://dx.doi.org/10.1017/CBO9780511754203

Hughes, A. 1997. Finance for SMEs: a UK perspective, Small Business Economics 9: 151-166. http://dx.doi.org/10.1023/A:1007971823255

Hughes, A.; Storey, D. 1994. Finance and the Small Firm. London: Routledge.

Jansen, E. S.; Teräsvirta, T. 1996. Testing parameter constancy and super exogeneity in econometric equations, Oxford Bulletin of Economics and Statistics 58: 735-763.

http://dx.doi.org/10.1111/j.1468-0084.1996.mp58004008.x

Keasey, K.; McGuinness, P. 1990. Small new firms and the return to alternative sources of finance, Small Business Economics 2: 213-222. http://dx.doi.org/10.1007/BF00389529

Myers, S. C.; Majluf, N. S. 1984. Corporate financing and investment decisions when firms have information that investors do not have, Journal of Financial Economics, 187-221. http://dx.doi.org/10.1016/0304-405X(84)90023-0

OECD 2009. The Impact of the Global Crisis on SME and Entrepreneurship Financing and Policy Responses. Paris: OECD. 
Peek, J.; Rosengren, E. S. 1998. Bank consolidation and small business lending: it's not just bank size that matters, Journal of Banking and Finance 22(6-8): 799-819.

http://dx.doi.org/10.1016/S0378-4266(98)00012-0

Rajan, R.; Zingales, L. 1998. Financial dependence and growth, American Economic Review 88: 559-587.

Remolona, E. M. 1993. The recent growth of financial derivative markets, Federal Reserve Bank of New York Quarterly Review 17(4) (Winter): 28-43.

Strahan, P. E.; Weston, J. 1996. Small business lending and bank consolidation: is there cause for concern, Current Issues in Economics and Finance Vol. 2 (March). Federal Reserve Bank of New York.

Sufian, F.; Habibullah, M. S. 2009. Determinants of bank profitability in a developing economy: empirical evidence from Bangladesh, Journal of Business Economics and Management 10(3): 207-217. http://dx.doi.org/10.3846/1611-1699.2009.10.207-217

Teräsvirta, T. 1994. Specification, estimation and evaluation of smooth transition autoregressive models, Journal of the American Statistical Association 89(425): 208-218.

http://dx.doi.org/10.2307/2291217

Jer-Shiou CHIOU. Professor, Department of Finance and Banking, Shih-Chien University, Taiwan; 70, Ta-Chih St., Taipei 104, Taiwan.

I was born in Taipei, Taiwan in 1960, received my master in 1990 at University of Iowa, doctorate in 1994 at University of Missouri - Columbia. I became an associate professor at China University of Technology and been a chairperson at department of international trade for 10 years. After that, I taught economics and finance relevancy at department of Finance and Banking, Shih-Chien University, as a full professor.

Recent researches are concerning about stock returns' volatility, and SME's lending related topics. Interdisciplinary topics are also studied, such as the interaction between energy and financial market. Instead of performing theoretical deriving; econometrics formation is the means when I do my work. I regularly received article reviewing invitation from international journals such as: Small Business Economics, Energy Economics, Energy, Physica A, Applied Financial Economics, Applied Economics, Quantitative Finance, and International Review of Financial Analysis. I have been listed in Marque's "Who's Who in the World," 2009 and 2011.

Bor-Yi HUANG. Professor, Department of Finance and Banking, Shih-Chien University, Taiwan; 70, Ta-Chih St., Taipei 104, Taiwan.

Pei-Shan WU. Assistant Professor, Department of Finance, Ching Yun University, Taiwan; No. 229, Jianxing Road, Zhongli City, Taoyuan County 320, Taiwan.

Chun-Ni TSAI. Graduate student at the Department of Finance and Banking, Shih-Chien University, Taiwan. 